\title{
First report of Botryosphaeria dothidea causing shoot blight and cankers of pistachio in Australia
}

\author{
Nicola Wunderlich • Severino Sousa Costa • \\ Roni Pati Tpoi • Gavin James Ash
}

Received: 10 October 2011 / Accepted: 3 February 2012 /Published online: 25 February 2012

(C) Australasian Plant Pathology Society Inc. 2012

\begin{abstract}
Shoot blight and cankers are reported for the first time from pistachio in Australia from 20-26 year old trees of a plantation in the Riverina, South West NSW. Shoot blight symptoms during late summer prior to harvest included dark lesions on current-season shoots, followed by blackening and dieback of the same structures. Cankers were observed in older wood, showing wedge-shaped discolouration in cross-sections of these branches. Microscopic investigation provided evidence of black pycnidia, indicative of Botryosphaeriaceae, on the surface of old cankerous wood. Isolations from surface sterilised symptomatic young shoots and old wood yielded in Botryosphaeriaceae cultures, which were identified via conidia morphology and ITS sequencing. All isolates were identified as the pistachio pathogen Botryosphaeria dothidea responsible for panicle and shoot blight as well as basal cankers of pistachio in other parts of the world. Pathogenicity from six of our isolates was confirmed with in vitro pathogenicity tests. Re-inoculation of actively growing cultures from our isolates into healthy young pistachio wood resulted in dark internal lesions varying between 5 and $40 \mathrm{~mm}$ length, while control inoculated wood showed no lesions or internal discolouration.
\end{abstract}

Keywords Pistacia vera · 'Bot' canker · Panicle and shoot blight

N. Wunderlich $(\bowtie) \cdot$ G. J. Ash

EH Graham Centre for Agricultural Innovations, Charles Sturt University,

Locked Bag 588,

Wagga Wagga 2678, NSW, Australia

e-mail: nwunderlich@csu.edu.au

S. S. Costa $\cdot$ R. P. Tpoi

Ministry of Agriculture and Fisheries,

Rua Nicolau Lobato No. 5,

Comoro, Dili, Timor-Leste
The pistachio nut (Pistacia vera L.) cultivation in Australia is a relatively new industry, with first commercial cropping in late 1980s. Currently the industry extends over 3 states along the Murray River in New South Wales (NSW), Victoria (VIC) and South Australia (SA) as well as individual orchards in Southern and central NSW, VIC and SA. The current total area of cultivation in Australia comprises 870 ha (2009 data) and has an annual production value of AU\$ 9 million (95\% dry market and $5 \%$ fresh nuts). The production in Australia covers $40 \%$ of the countries consumption and currently does not supply any export markets.

The three major diseases reported from pistachio in Australia at current are pistachio anthracnose, a leaf spot and hull rot caused by Colletotrichum acutatum (Ash and Lanoiselet 2001a), late blight, affecting leaves and fruit caused by Alternaria alternata (Ash and Lanoiselet 2001b) and pistachio dieback caused by Xanthomonas bacterial pathogens (Facelli et al. 2002).

Visual observations during the growing season 2010/ 2011 of a decline in a pistachio orchard in the Riverina, south-western NSW, Australia, with 20-26 year old trees, showed initial dark lesions on current-season shoots, which later in the season blackened completely and died off (Fig. 1). In addition the older wood of affected trees showed cankers on stems and branches, which revealed discolouration of wood in cross-sections. Microscopic investigation of the bark on the older cankerous wood showed black pycnidia covering the wood surface (Fig. 2).

Samples of symptomatic current-season shoots and older wood were taken between harvest and pruning season and surface sterilised in $0.5 \%$ sodium hypochlorite for $2 \mathrm{~min}$ followed by three consecutive rinses with sterile distilled water for $1 \mathrm{~min}$ each, placed in potato dextrose agar (PDA; Oxoid Ltd., Basingstoke, Hampshire, England) and incubated at $25^{\circ} \mathrm{C}$ in the dark. Mycelium indicative of 


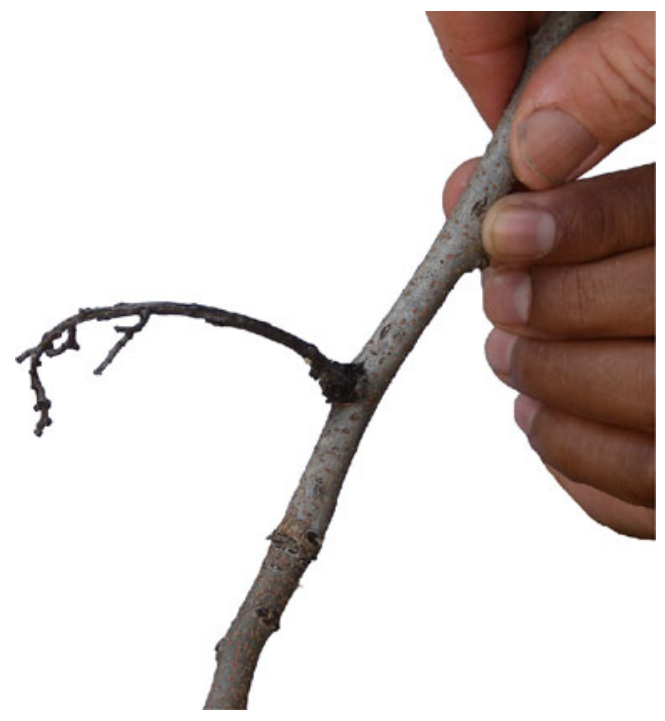

Fig. 1 Darkening and dying of current-season twigs hosting Botryosphaeria dothidea

Botryosphaeriaceae growth was subcultured onto PDA after 3 days. Individual cultures were further incubated for 2 weeks and after blackening of the mycelium occurred the cultures were inspected for pycnidia inside and on the surface of the PDA. Microscopic investigation of crushed up pycnidia showed thin-walled conidia ranging from 21 to $25 \mu \mathrm{m}$ in length and 5-6 $\mu \mathrm{m}$ width (Fig. 3). Conidia morphology matched the description of the anamorph Fusicoccum aesculi. To further confirm species and identify the holomorph, the ribosomal DNA internal transcribed spacer region of six single spore isolates was amplified and sequenced using ITS1 and ITS4 primers (White et al. 1990). Sequences were compared to sequences in GenBank using the Basic Local Alignment Search Tool. Based on the sequencing data combined with conidia morphology, the fungal cultures were identified as Botryosphaeria dothidea

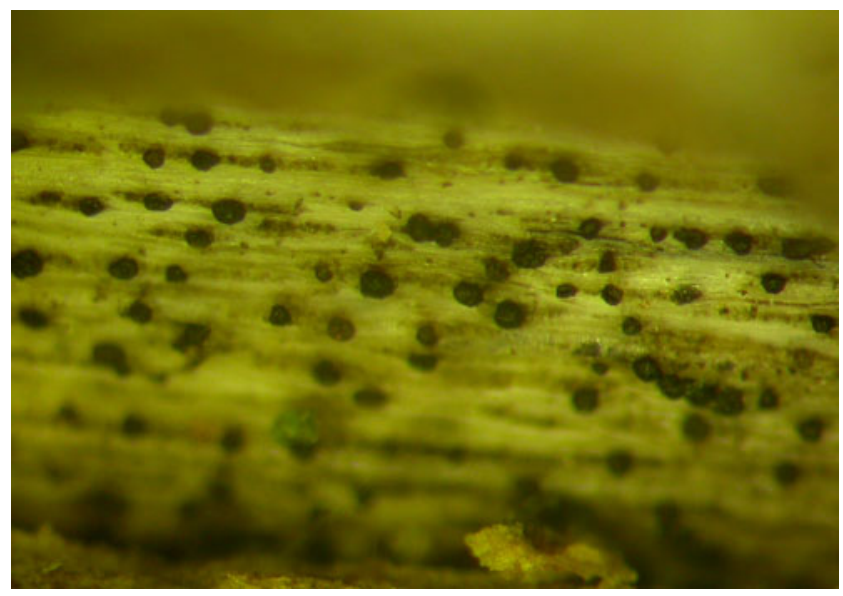

Fig. 2 Black pycnidia covering the bark surface of cankerous pistachio wood
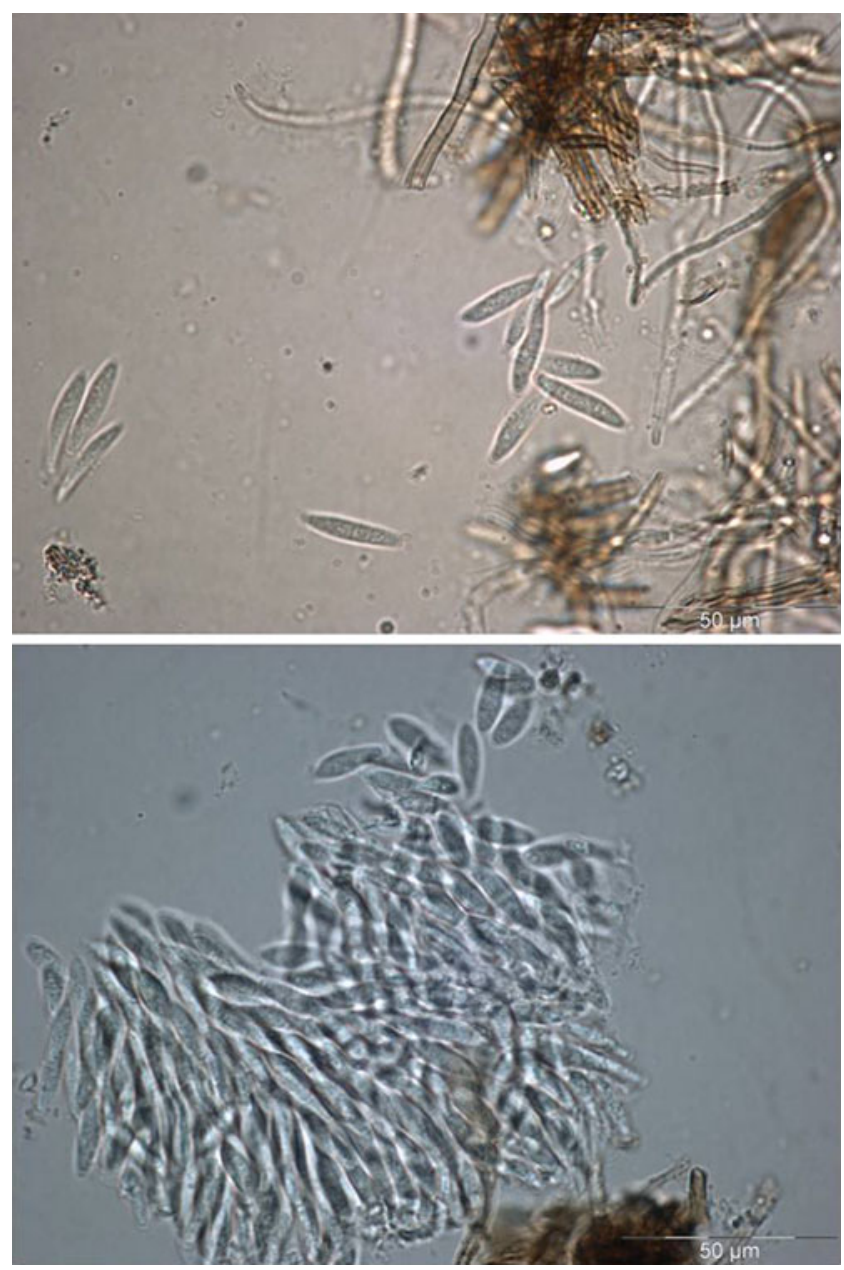

Fig. 3 Hyaline conidia from pycnidia of Botryosphaeria dothidea cultures

(Mough.: Fr.) Ces. \& De Not.(anamorph: Fusicoccum aesculi).

The isolates in this study are stored at the Agricultural Scientific Collection Unit, Department of Primary Industries NSW, Orange, NSW, Australia (Herbarium code: DAR) and corresponding DNA sequences were deposited in GenBank. Accession numbers are listed in Table 1.

Table 1 Herbarium and GenBank accession numbers for six isolates used in this study

\begin{tabular}{lll}
\hline Isolate & DAR accession number & GenBank accession number \\
\hline D1 & 81463 & JN561085 \\
D2 & 81464 & JN561086 \\
D3 & 81465 & N561087 \\
D5 & 81468 & JN561088 \\
D7 & 81467 & JN561089 \\
D8 & 81466 & JN561090 \\
\hline
\end{tabular}


To confirm pathogenicity an experiment re-inoculating the six $B$. dothidea isolates (Table 1) into healthy looking $\sim 10 \mathrm{~mm}$ in diameter and $80 \mathrm{~mm}$ long cuttings of pistachio wood, was conducted. Wood samples were surface sterilised with $70 \%$ ethanol and wounded by drilling a hole with a surface-sterilised $4 \mathrm{~mm}$ diameter drill bit into the pith in the middle of each piece of wood. Four mm mycelium plugs from actively growing 3 day old cultures of each of the six isolates were inserted into the holes in the pistachio wood. For each isolate there were five replicate wood pieces. All holes were covered with Parafilm and each piece of wood was placed into a Petri dish on moist filter paper. Control wood pieces were inoculated with sterile PDA plugs. Petri dishes were placed in a completely randomised design and incubated at $25^{\circ} \mathrm{C}$ in the dark. After 14 days the bark of each piece of wood was removed carefully with a sterile dissecting blade and lengths of visible lesions originating from the inoculation point were recorded. No lesions or discolouration in the cross sections of control inoculated wood were recorded. Lesion lengths for the wood inoculated with $B$. dothidea ranged from $5 \mathrm{~mm}$ to $40 \mathrm{~mm}$.

To satisfy Koch's postulates small tissue samples were removed from the margin of healthy wood and lesion on each cane and plated out after surface sterilisation, as described above.

Fungi originating from these samples were identified to species level by their conidial morphology and were compliant with that of $B$. dothidea.

B. dothidea has been associated with pistachio panicle and shoot blight causing yield declines in California since 1991 (Michailides 1991) and this fungal species has also been identified as the cause of basal cankers on pistachio trees in South Africa (Swart and Blodgett 1998). In Australia the association of $B$. dothidea with $P$. vera has been limited to a single isolate from a root canker, submitted to the Agricultural Scientific Collection Unit, Department of Primary Industries NSW, Orange, NSW, Australia in 1987 (DAR 59086).

To the best of our knowledge our work presents the first report of $B$. dothidea causing stem canker and shoot blight of pistachio in Australia.

Acknowledgements The authors would like to thanks Bev and Dennis Lambert from Harefield Pistachios for access to their orchard and assistance with collecting samples as well as AusAID for the funding of training for Severino Costa and Roni Tpoi at Charles Sturt University, Wagga Wagga.

\section{References}

Ash GJ, Lanoiselet VM (2001a) DISEASE NOTES OR NEW RECORDS: first report of Colletotrichum acutatum causing a leaf spot and hull rot of pistachio. Australas Plant Pathol 30 (4):365-366. doi:10.1071/AP01050

Ash GJ, Lanoiselet VM (2001b) First report of Alternaria alternata causing late blight of pistachio (Pistacia vera) in Australia. Plant Pathol 50(6):803-803. doi:10.1046/j.1365-3059.2001.00626.x

Facelli E, Taylor C, Scott E, Emmett R, Fegan M, Sedgley M (2002) Bacterial dieback of pistachio in Australia. Australas Plant Pathol 31(1):95-96. doi:10.1071/ap01072

Michailides TJ (1991) Pathogenicity, distribution, sources of Inoculum, and infection courts of Botryosphaeria dothidea on Pistachio. Phytopathology 81:566-573

Swart WJ, Blodgett JT (1998) First report of Botryosphaeria dothidea basal canker of pistachio trees in South Africa. Plant Dis 82 (8):960-960. doi:10.1094/pdis.1998.82.8.960a

White TJ, Bruns T, Lee S, Taylor J (1990) Amplification and direct sequencing of fungal ribosomal RNA genes for phylogenetics. In: Innis MA, Gelfand DH, Sninsky JJ, White TJ (eds) A guide to methods and applications. Academic, San Diego, pp 315-322 